\title{
Lipolytic Effect of Eumicrotremus orbis Water Extracts in Differentiated 3T3-L1 Adipocytes
}

\author{
Byoung-Mok Kim ${ }^{1,2}$, Heang-Jeun $\mathrm{Heo}^{2}$, Dong-Soo Kim ${ }^{3}$, Young-Myung Kim ${ }^{4}$, In-Hack Jeong ${ }^{5}$, \\ Young-Min Chi' ${ }^{1, *}$
}

${ }^{1}$ Division of Biotechnology, College of Life Sciences and Biotechnology, Korea University, Seoul, Korea

${ }^{2}$ Division of Metabolism and Functionality Research, Korea Food Research Institute, Seongnam, Korea

${ }^{3}$ Jeonbuk Institute for Bioindustry, Jeonju, Korea

${ }^{4}$ Gi-jang Mulsan Col., Busan, Korea

${ }^{5}$ Division of Marine Food Bioscience \& Technology, Gangneung National University, Gangneung, Korea

\section{Email address:}

bmkim@kfri.re.kr (Byoung-Mok K.), ezeg@korea.ac.kr (Young-Min C.), mistltoe@kfri.re.kr (Heang-Jeun H.), dskim@jib.re.kr (Dong-Soo K.), ymkim6321@naver.com (Young-Myung K.), ihjeong@gwnu.ac.kr (In-Hack J.)

\section{To cite this article:}

Byoung-Mok Kim, Heang-Jeun Heo, Dong-Soo Kim, Young-Myung Kim, In-Hack Jeong, Young-Min Chi. Lipolytic Effect of Eumicrotremus orbis Water Extracts in Differentiated 3T3-L1 Adipocytes. Clinical Medicine Research. Vol. 4, No. 1, 2015, pp. 69-74. doi: $10.11648 /$ j.ijnfs.20150401.20

\begin{abstract}
In this study, we investigated the effects of Eumicrotremus orbis water extracts (EOWE) on lipolysis in differentiatied 3T3-L1 adipocytes and its mechanism. It was observed that there was no cytotoxicity for adipocytes of EOWE. The content of glycerol released in cell culture medium increased dependent on sample concentration. In differentiated 3T3-L1 adipocytes treated EOWE, hormone sensitive lipase (HSL) and phosphorylated HSL (p-HSL) protein level increased by approximately 3.43 and 1.77 times as compared to the controls. But, adipose triglyceride lipase (ATGL) protein level did not effect as compared to the controls. Treated EOWE inhibited the protein expression of perilipin A. In other word, it is judged to be due to, a content of glycerol released in cell culture medium increased through not only increase of HSL, p-HSL and p-PKA protein level, but inhibit of perilipin A. Therefore, our results suggest that EOWE may induce lipoylsis by increasing the protein levels of HSL, p-HSL and p-PKA.
\end{abstract}

Keywords: Lipolytic Effect, Eumicrotremus Orbis, 3T3-L1 Adipocytes, Anti-Obesity, Marine Resource

\section{Introduction}

Due to the rapid economic growth and improvement of living standards, Korea's dietary patterns changed quickly. Furthermore, due to the development of science technologies including automobiles, energy consumption has reduced, resulting in an increase in obese populations. Obesity occurs due to various reasons including genetics, environment and social factors. However, it is caused when the energy remaining in the body is greater than the energy consumed, causing it to change into neutral fat and accumulate in the body [1]. Likewise, obesity results from the adjusting process of fat accumulation and storing energy [2], and causes chronic diseases including diabetes, high blood pressure and cardiovascular diseases due to the excessive lipid accumulation in fat cells [3]. Lipid droplets inside the fat cells are known to play an important role in the metabolism and adjustment of lipids. It is widely accepted that the decomposition of neutral fats within the lipid droplet and the resulting discharge of glycerol is an important mechanism for adjusting lipid accumulation within cells [4]. In other words, studies for developing anti-obesity materials usually use methods to suppress fat cell division processes or promote fat decomposition with the goal of suppressing the excessive accumulation of neutral fats in fat tissues. Major enzymes related to the adjustment of lipid metabolism are lipoprotein lipase (LPL), acyl-CoA synthetase (ACS), and hormone sensitive lipase (HSL) [5-7]. HSL has been recognized as a very important lipase for the fat decomposition process and it receives hormone adjustment such as insulin and epinephrine According to the molecular mechanism, decomposition of triglyceride results from protein kinase A (PKA) or the HSL phosphorylation process of HSL due to G protein coupled receptors and cyclic AMP activated extracellular signal 
regulated kinase (ERK) [8]. It was recently revealed that adipose triglyceride lipase (ATGL) is a fat decomposition enzyme that has a special effect on triglyceride, and this is viewed as an enzyme that has an effect on the generation of diglyceride, which is the first stage for fat decomposition [911]. It is believed that perilipin A protein that exists in the membrane part of the lipid droplet suppresses fat decomposition, and its mechanism is understood to interfere with fat decomposition enzymes such as HSL and ATGL from approaching the lipid droplet to suppress the effects of enzymes and substrate [12]. Despite its excellent effects, obesity treatment developed up until now has many issues due to side effects such as strokes and spasms. Therefore, research is being actively conducted to find functional materials and reveal active mechanisms from natural plants in order to address such issues regarding side effects. Eumicrotremus orbiss are cold-sea fish that live in the cold seas of the Northern Pacific such as the Korean East Sea, Sea of Okhotsk, Pacific waters of Kuril, Aleutian Islands and Kamchatka, Bering Sea and in the waters of North America to south to British Columbia [13]. In Gangwon Province it is called shimtungi and is a fish popularly cooked in stews due to its effects on relieving hangovers and recovering liver functions. The main active ingredients are collagen and chondroitin sulfate and they are reported to have antibacterial [14], anti-cancer [15,16], and immunity adjustment [17] effects. Consequently, there has been the increased interest in preventing lipid accumulation or stimulating lipolysis of adipocyte triglyceride (TG). In this study, in order to evaluate the anti-obesity effects of Eumicrotremus orbis, which has never been performed yet, the active mechanism and effects in in vitro 3T3-L1 fat cells were verified.

\section{Materials and Methods}

\subsection{Preparation of Extracts}

Eumicrotremus orbis water extracts (EOWE) were extracted three times in six hours at $100^{\circ} \mathrm{C}$ by adding distilled water of 20 times the amount $(\mathrm{w} / \mathrm{v})$ in freeze-dried Eumicrotremus orbis powder using a round flask attached with a reflux condenser vertically. After extraction, centrifugation (SUPRA 22K, HANIL, Korea) was carried out for $20 \mathrm{~min}$ at $6000 \mathrm{rpm}$, and the supernatant obtained after filtration (No 2C, WHATMAN, England), it was freeze-dried (PVTFD30R, ILSHINBIOBASE, Korea). The freeze-dried powder was stored at a $-70^{\circ} \mathrm{C}$ freezer to be used as specimens for analysis.

\subsection{Cell Culture and Differentiation}

3T3-L1 pre-adipocyte cells were obtained from the Korean Cell Line Bank (Seoul, Korea). The cells were maintained in Dulbeccos Modified Eagles Medium (DMEM; Welgene Inc., Daegu, Korea) high glucose containing $10 \%$ BCS and $1 \%$ $(\mathrm{v} / \mathrm{v})$ penicillin-streptomycin $(100 \mathrm{units} / \mathrm{mL}$ penicillin and $100 \mu \mathrm{g} / \mathrm{mL}$ streptomycin) at $37{ }^{\circ} \mathrm{C}$ in $5 \% \mathrm{CO}_{2}$. Fresh medium were provided to the cells every 2 days till cells were about $80 \%$ confluence. As described previously [29], 3T3-L1 preadipocytes were seeded into 6-well plates at a density of $1 \times 10^{5} \quad$ cells/well to differentiate pre-adipocytes into adipocytes and grown to confluent in 3 days. And then preadipocytes were stimulated for 3 days with a differentiation medium ( $10 \%$ fetal bovine serum (FBS)/DMEM medium supplemented with $0.25 \mathrm{mM}$ 3-isobutyl-1-methylxanthine (IBMX), $0.5 \mu \mathrm{M}$ dexamethasone and $1.0 \mu \mathrm{M} / \mathrm{mL}$ insulin). On day 3 , the medium was replaced with maturation medium (10\% FBS/DMEM medium and $1.0 \mu \mathrm{M} / \mathrm{mL}$ insulin) for an additional 2 days. On day 5, the culture medium was replaced again with only $10 \% \mathrm{FBS} / \mathrm{DMEM}$, which were changed every two days until day 9 . At this time, the EOWE treatment was performed after adipocytes differentiation of the 3T3-L1 cells, and then incubated for $24 \mathrm{hr}$. The control was treated with same medium without EOWE.

\subsection{Cell Viability}

Effects of EOWE on the survival rate of cultured cells were measured using 3-(4,5-dimethylthiazol-2-yl)-2,5diphenyltetrazolium (MTT) assay, which is based on the conversion of MTT to MTT-formazan by mitochondrial enzyme. The cells were grown in 96-well plates (Corning, USA) at a density of $5 \times 10^{4}$ cells/well, and were incubated at $37^{\circ} \mathrm{C}$ for $24 \mathrm{hr}$. The cells were washed with fresh medium, and were treated with control medium or the medium supplemented with EOWE $(100,200,400 \mu \mathrm{g} / \mathrm{mL})$. After incubation for $24 \mathrm{hr}$, the cells were rewashed with fresh medium, and then $100 \mathrm{uL}$ of MTT solution $(1 \mathrm{mg} / \mathrm{mL})$ was added and incubated at $37^{\circ} \mathrm{C}$ for $4 \mathrm{hr}$. Finally, $100 \mu \mathrm{L}$ of DMSO was added to solubilize the formed formazan crystals, and the amount of formazan crystal was determined by measuring the absorbance at $450 \mathrm{~nm}$ using microplate reader. Viability of cells was quantified as a percentage compared to the control and dose response curves were developed.

\subsection{Determination of Glycerol Release}

Lipolysis was assessed through the measurement of glycerol released (Free glycerol reagent, Sigma, St. Louis, MO, USA) into the medium, according to the manufacturer's instructions. Briefly, differentiated 3T3-L1 adipocytes were treated with EOWE for $24 \mathrm{hr}$. After incubation, $50 \mu \mathrm{L}$ of the medium was incubated with $200 \mu \mathrm{L}$ of a Free Glycerol Reagent at $70^{\circ} \mathrm{C}$ for $10 \mathrm{~min}$. The glycerol was quantified by measuring absorbance at $540 \mathrm{~nm}$ using microplate reader. Glycerol release was quantified as a percentage compared to the control.

\subsection{Western Blot Analysis}

Cultured differentiated cells were washed twice with icecold phosphate buffered saline (PBS), and ice-cold lysis buffer $(50 \mathrm{mM}$ tris- $\mathrm{HCl}$ [pH 7.4], 1\% NP-40, 0.25\% sodium deoxycholate, $150 \mathrm{mM} \mathrm{NaCl}, 1 \mathrm{mM}$ EDTA, $1 \mathrm{mM}$ PMSF, 1 $\mathrm{mM}$ sodium orthovanadate, $1 \mathrm{mM} \mathrm{NaF}, 1 \mathrm{~g} / \mathrm{mL}$ aprotinin, 1 $\mathrm{g} / \mathrm{mL}$ leupeptin, $1 \mathrm{~g} / \mathrm{mL}$ pepstatin) was added, and then 
reacted at $4^{\circ} \mathrm{C}$ for $1 \mathrm{hr}$, and the centrifugation was carried out for 30 minutes at $14000 \mathrm{rpm}$ to separate the supernatant. The total protein of cell lysate was quantified using the Bio-rad protein quantification reagent (bio-rad, Hercules, CA, USA), and its method. Laemmli sample buffer (Bio-rad) with the same cell lysate was mixed to make the sample, and then $8 \%$ sodium dodecyl sulphate (SDS)-polyacrylamide gel was used to separate protein with electrophoresis, and was transmitted through electro blotting through nitrocellulose membrance (Bio-rad). 5\% skim milk was treated on the nitrocellulose membrance on which the separated protein was spread to conduct blocking for non-specific proteins, and first antibody (1:1000 dilution, Cell signaling) was treated and were incubated overnight at $4^{\circ} \mathrm{C}$. And then it was cleaned with PBS-T, and anti-rabbit IgG antibody (1:2500, Cell signaling) was conjugated for $1 \mathrm{hr}$ at room temperature. After the reaction, enhanced chemiluminoesence (ECL) solution (Amersham Life Science Corp) was applied in a dark room and sensitized with $\mathrm{x}$-ray to analyze the revelation amount of specific protein. For normalization, the membranes were reprobed with antibodies against GAPDH (1:5000 dilution, Cell signaling). Several exposure times were used to obtain the signals in the linear range.

\subsection{Statistical Analysis}

For the results of this experiment, means and standard deviation were computed using a statistical analysis program (SPSS package program v18.0, SPSS Inc., Chicago, IL, USA). The average value analysis of the two groups verified the significant difference at $p<0.05$ using independent t-test, and the average value analysis of three or more groups were carried out according to the one-way analysis of variance (ANOVA) method. Significance of mean values was tested using Duncan's multiple comparison test $(P<0.05)$.

\section{Results and Discussion}

\subsection{Cell Viability of EOWE on 3T3-L1 Adipocytes}

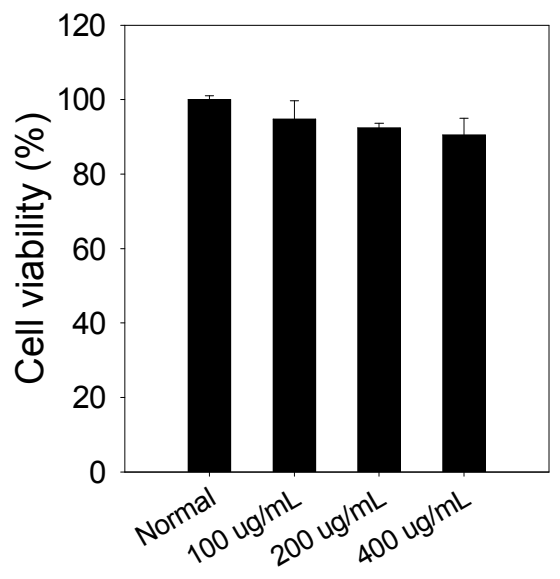

Fig. 1. Cell viability of mature 3T3-L1 adipocytes, determined by MTT reagent, with treatment of Eumicrotremus orbis water extract at various concentrations. Significant differences were determined by Duncan's multiple range test at $p<0.05$.
To examine the cytotoxicity of EOWE in 3T3-L1 adipocytes, MTT assay test was conducted at concentration levels of 100, 200 and $400 \mu \mathrm{g} / \mathrm{mL}$, as shown in Fig. 1. MTT assay is a testing method using the abilities of mitochondria that returns MTT tetrazolium. It is one of the most representative testing methods to examine cell proliferation and growth, and the absorbance increases in proportion to the number of cells. There was almost no change in the overall survival rate of adipocytes according to the concentration of EOWE. Althought there was slightly decreased in cell viability as compared to the control group, it did not show significant differences $(P<0.05)$.

\subsection{The Content of Glycerol Released in Cell Culture Medium Treated EOWE}

The triacyglycerols (TAG) in adipose cells break down to free fatty acids and glycerol by lipases, and in the case of human, it is separated into the blood, and then is transported to the liver $[18,19]$. Therefore, to investigate the content of free glycerol in cell culture medium, in the 3T3-L1 adipocytes system, can be an indicator that shows a TAG in adipose cells hydrolyzed by lipases. We investigated the content of glycerol released in cell culture medium after $24 \mathrm{hr}$ incubation with EOWE, as shown in Fig. 2. All treated EOWE group increased the content of free glycerol by approximately $7.6 \%, 22.8 \%$ and $47.7 \%$ as compared to the controls, and the content of free glycerol were significantly increased dependent on extracts concentration $(\mathrm{P}<0.05)$. These results is considered that EOWE stimulated lipolysis through induction of lipases, and stored TAG in adipose tissue hydrolyzed to free fatty acid and glycerol, resulting in increased the content of free glycerol in culture medium. Ahn et al. [20] reported that when treating kim-chi extracts with adipocytes, the content of free glycerol in culture medium increased significantly. In such a case, EOWE might also show the same as our results indicated.

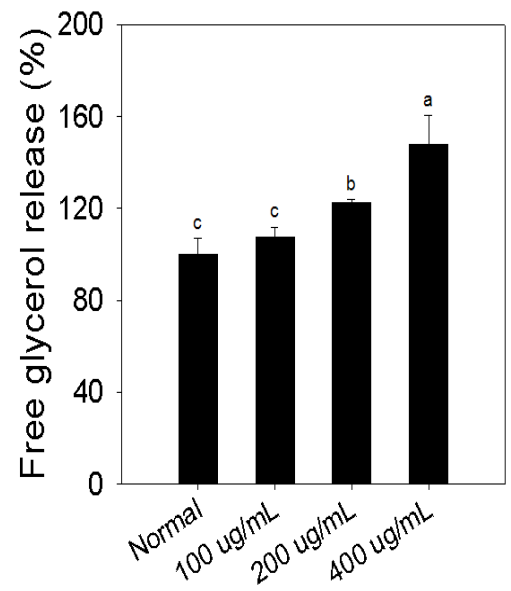

Fig. 2. Stimulatory effect of Eumicrotremus orbis water extract on glycerol release in 3T3-L1 adipocytes. The values were calculated as a percentage of free glycerol content of the differentiated control cells not treated with Eumicrotremus orbis water extract. It was treated for $24 \mathrm{hr}$ by sample concentration. Each value is expressed as the mean $\pm S D$ of three independent experiments. Significant difference compared to control group at $p<0.05$. 


\subsection{Effects of EOWE on Expression of Protein Related to Fat Decomposition}

Lipolysis is a catabolic process that hydrolyzes stored TAG in adipose tissue to release free fatty acids and glycerol by lipases such as HSL, ATGL, perilipin A [21]. HSL is the most important lipase effector of lipolysis in adipocytes [22,23], and HSL-dependent lipolysis is mediated by protein kinase A (PKA)-dependent phosphorylation of perilipin A $[21,24]$. In order words, lipolysis in adipocytes can regulate by lipases such p-PKA, p-HSL, HSL, ATGL and Perilipin A. Thus, in this study, to evaluate the lipolytic effect of EOWE in differentiated 3T3-L1 adipocytes, we investigated the protein level of p-PKA, p-HSL, HSL, ATGL and perilipin A by western blotting analysis, as shown in Fig. 3. We observed increased the protein expression of p-PKA in a dosedependent manner. In other words, the protein expression of p-PKA in adipocytes treated EOWE for $24 \mathrm{hr}$ was significantly increased in a dose-dependent manner by approximately $59.1 \%, 157.5 \%$ and $299.9 \%$ as compared to the controls $(P<0.05)$. Also we observed increased the protein expression of p-HSL in adipocytes treated EOWE for $24 \mathrm{hr}$ was significantly increased in a dose-dependent manner by approximately $13.5 \%, 347.5 \%$ and $343.1 \%$ as compared to the controls $(P<0.05)$. As well as, the protein expression of HSL was significantly increased in a dose-dependent manner by approximately $8.9 \%, 52.1 \%$ and $68.2 \%$ as compared to the controls $(P<0.05)$. Holm et al. [25,26] reported that lipoylsis was increased through HSL phosphorylation by having epinephrine and glucagon stimulate adenylate cyclase. Ahn et al. [20] reported that lipolysis was increased due to kim-chi extracts increasing mRNA of HSL in adipocytes. In other words, this results is considered that the EOWE decomposed TG through not only phosphrylation of PKA, but also phosphorylation of HSL and stimulation of HSL. To investigate the lipolytic effect of EOWE in differentiated 3T3-L1 adipocytes, the protein expression of ATGL was examined, as shown in Fig. 3. In results, the protein expression of ATGL was significantly increased in a dosedependent manner, but lower than as compared to the controls $(P<0.05)$. In recent, ATGL hs been found to be predominantly responsible for the fist step of TG hydrolysis $[27,11,16]$, and first acts on TG to hydrolyze a fatty acyl chain [28]. Thus, the level of glycerol released from the adipocytes is mainly dependent on cellular expression of lipase such as HSL and ATGL. This results is considered that the EOWE didn't influence the protein expression of ATGL, resulting in didn't contribute on hydrolysis to be free fatty acid and glycerol from TG. perilipin A, which incorporates into the compartment membrane of lipid droplets, inhibits the lipolysis by preventing both HSL and ATGL from TG access in the core of lipid droplets [12]. This demonstrate that if the extracts inhibit the expression of perilipin A, the expression of HSL and ATGL increase, resulting in TG break down with free fatty acid and glycerol. We observed decreased the protein expression of perilipin A as compared to the controls $(P<0.05)$. In other words, the protein expression of perilipin
A in 3T3-L1 adipocytes treated EOWE for 24hr was significantly decreased in a dose-dependent by approximately $13.16 \%, 15.67 \%$ and $19.73 \%$ as compared to the controls $(P<0.05)$. In other words, suppression of perilipn A protein, which is known to be an enzyme that interferes with fat decomposition enzymes of HSL and ATGL to approach lipid droplet, was found to be more effective in EOWE compared to the control. Such results imply that through treated EOWE in differentiated 3T3-L1 adipocytes, increased the protein expression of HSL and phosphorylation of HSL, resulting in TG break down with fatty acids and glycerol, and increased in a dose-dependent manner the content of glycerol released in culture medium. According to the results, it is considered that the EOWE may enhance lipolysis through not only increasing the protein levels of p-PKA, p-HSL and HSL, but inhibiting the protein levels of perilipin A.
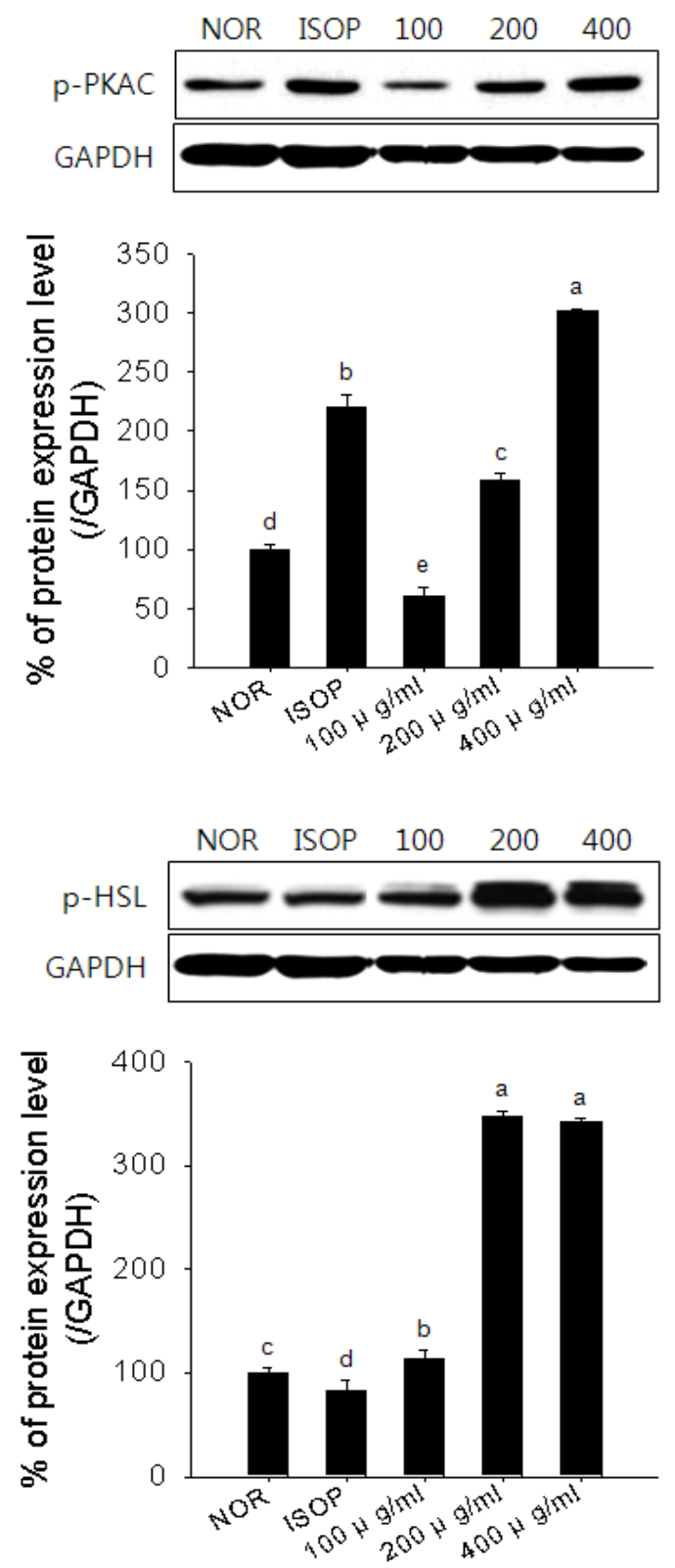

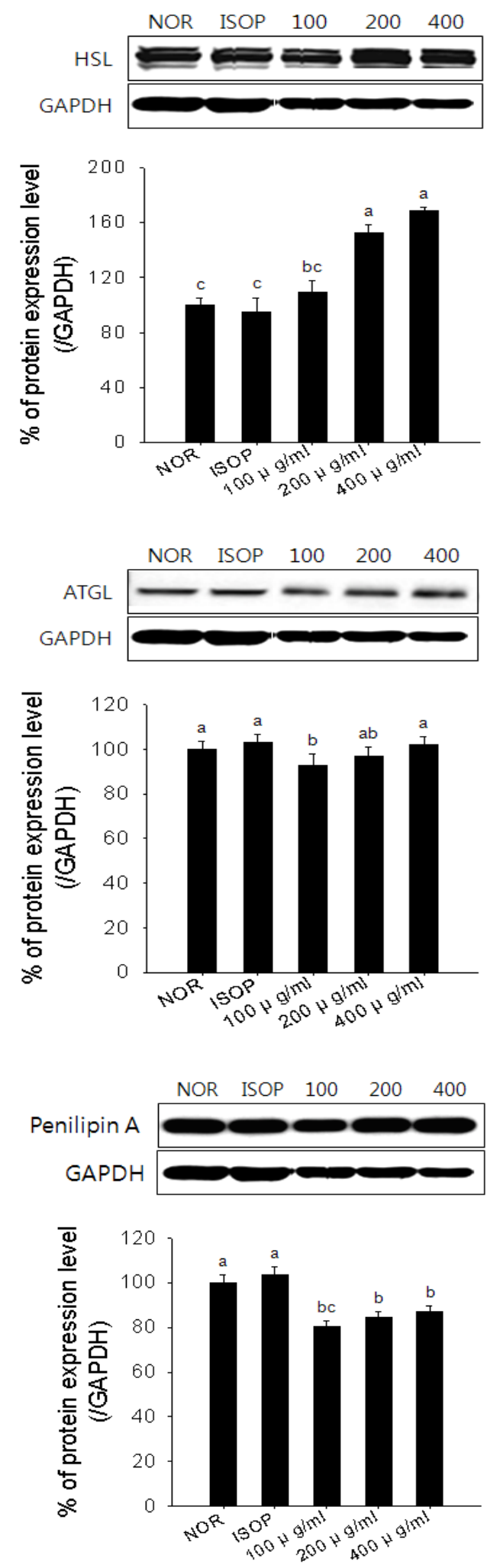

Fig. 3. Effect of Eumicrotremus orbis water extract on protein expression in 3T3 L1 adipocytes. 3T3 L1 adipocyte cells was cultured for 9 days. Each concentrated sample was added after differentiation. The results expressed as a ratio of GAPDH. The protein expression level is presented as means(bar) with SD(error bar). Significant differences between treated and untreated $3 T 3$ L1 adipocytes were determined using a T test $(p<0.05)$. Western blot of p-PKA, p-HSL, HSL, ATGL and perilipin $A$ in differentiated $3 T 3$ L1 adipocytes treated for $24 \mathrm{hr}$ by sample concentration. HSL, hormone sensitive lipase.

\section{Conclusions}

In this study, we investigated the effect of Eumicrotremus orbis water extracts (EOWE) on lipolysis in differentiated 3T3-L1 adipocytes. EOWE did not have toxicity in adipocytes at concentrations in a dose-dependent manner. The content of free glycerol in cell culture medium increased dependent on sample concentration. We observed increased the protein level of p-PKA, p-HSL and HSL, when EOWE treated several concentration in differentiated 3T3-L1 adipocytes, also inhibited the protein level of perilipin A. Such results imply that through treated EOWE in differentiated 3T3-L1 adpocytes, increased the protein expression of HSL, phosphorylation of HSL and PKA, resulting in TG break down to fatty acids and glycerol, and increased in a dose-dependent manner the content of glycerol released in cell culture medium. Therefore, these results suggest that EOWE could be useful for prevention or treatment of obesity by its stimulatory lipolysis.

\section{Acknowledgments}

This study was supported, in part, by grants from the Korea Food Research Institute (E0143023793), Korea.

\section{References}

[1] Albu, J.; D Allison, C.N.; Boozer, S.; Heymsfield, H.; Kissileff, A.; Kretser, K.; Krumhar, R.; Leibei, C.; Nonas, X.; PiSunyer, T.; Vanltallied, E. Obesity solutions: report of a meeting. Nutr. Res. 1997, 55, 150-156.

[2] Spiegelman, B.M.; Flier, S. Adipogenesis and obesity; rounding out the big picture. Cell. 1996, 87, 377-389.

[3] Visscher, T.L. The public health impact of obesity. Annu. Rev. Publ. Health. 2001, 22, 355-375.

[4] Frayn, K.N.; Karpe, F.; Fielding, B.A.; Macdonald, I.A.; Coppack, S.W. Integrative physiology of human adipose tissue. Int. J. Obes. Relat. Metab. Disord. 2003, 27, 875-888.

[5] Chiu, K.M.; Schmidt, M.J.; Shug, A.L.; Binkley, N.; Gravenstein, S. Effect of dehydroepiandrosterone sulfate on carnitine acetyl transferase activity and L-carnitine levels in oophorectomized rats. Biochim. Biophys. Acta. 1997, 1344, 201-209.

[6] Mead, J.R.; Irvine, S.A.; Ramji, D.P. Lipoprotein lipase: structure, function, regulation, and role in disease. J. Mol. Med. 2002, 80, 753-769.

[7] Ryu, M.H.; Daily, J.W.; Cha, Y.S. Effect of starvation on hepatic acyl-CoA synthetase, carnitine palmitoyltransferase-I, and acetyl-CoA carboxylase mRNA levels in rats. Nutrition. 2005, 21, 537-542.

[8] Holm, C. Molecular mechanisms regulating hormonesensitive lipase and lipolysis. Biochem. Soc. Trans. 2003, 31, 1120-1124.

[9] Fushiki, H.; Hayakawa, Y.; Gomori, A.; Seo, T.; Tewari, S.; Ozaki, S.; Yoshimoto, R. In vivo imaging of obesity-induced inflammation in adipose tissue. Biochem Biophys. Res. Commun. 2010, 391, 674-678. 
[10] Jiang, B.; Yang, Y.; Jin, H.; Shang, W.; Zhou, L.; Qian, L.; Chen, M. Astragaloside IV attenuate lipolysis and improves insulin resistance induced by TNF $\alpha$ in 3T3-L1 adipocytes. Phytother. Res. 2008, 22, 1434-1439.

[11] Cha, S.Y.; Jang, J.Y.; Lee, Y.H. Lipolytic Effect of methanol extracts from luffa cylindrica in mature 3T3-L1 adipocytes. Kor. J. Soc. Food. Sci. Nutr. 2010, 39, 813-819.

[12] Akter, M.H.; Yamaguchi, T.; Hirose, F.; Osumi, T. Perilipin, a critical regulator of fat storage and breakdown, is a target gene of estrogen receptor-related receptor alpha. Biochem. Biophys. Res. Commun. 2008, 368, 563-568.

[13] Orlov, A.M.; Tokranov, A.M. Specific Features of Distribution, Some Features of Biology, and the Dynamics of Catches of Lumpsucker Aptocyclus ventricosus (Cyclopteridae) in Waters of the Pacific Ocean off the Kuril Islands and Kamchatka. $J$. Ichthyology. 2008, 48, 81-95.

[14] Li, J.Z.; Lian, E.C.Y. Aggregation of human platelets by acidic mucopolysaccharide extracted from Stichopus japonicus Selenka. Thrombosis. Haemostasis. 1988, 59 : 435.

[15] Okutani, K.; Morikawa, N. Gel filtration and sugar constituent of the polysaccharide extracted from the internal shell of squid. Bull. Japan. Soc. Sci. Fish. 1978, 44, 369-372.

[16] Okutani, K. Further investigation of the antitumor activity of the squid internal shell. Bull. Japan. Soc. Sci. Fish. 1982, 48, 421-424.

[17] Yamaguchi, T. Inhibitory activity of heat treated vegetables and indigestible polysaccharides on nutagenicity. Mutation. Research. 1992, 284, 205.

[18] Frayn, K.N.; Coppack, S.W.; Fielding, B.A.; Humphreys, S.M. Coordinated regulation of hormone-sensitive lipase and lipoprotein lipase in human adipose tissue in vivo: implications for the control of fat storage and fat mobilization. Adv. Enzyme. Regul. 1995, 35, 163-178.

[19] Liu, F.; Kim, J.; Li, Y.; Liu, X.; Li, J.; Chen, X. An extract of Lagerstroemia speciosa L. has insulin-like glucose uptakestimulatory and adipocyte differentiation-inhibitory activities in 3T3-L1 cells. J. Nutr. 2001, 131, 2242-2247.

[20] Ahn, I.S.; Do, M.S.; Kim, S.O.; Jung, H.S.; Kim, Y.I.; Kim, H.J.; Park, K.Y. Antiobesity effect of Kochujang (Korean fermented red pepper paste) extract in 3T3-L1 adipocytes. $J$. Med. Food. 2006, 9, 15-21.

[21] Ardévol, A.; Bladé, C.; Salvadó, M.J.; Arola, L. Changes in lipolysis and hormone-sensitive lipase expression caused by procyanidins in 3T3-L1 adipocytes. Int. J. Obes. Relat. Metab. Disord. 2000, 24, 319-324.

[22] Kim, S.K.; Kong, C.S. Anti-adipogenic effect of dioxinodehydroeckol via AMPK activation in 3T3-L1 adipocytes. Chem. Biol. Interact. 2010, 186, 24-29.

[23] Frayn, K.N.; Coppack, S.W.; Fielding, B.A.; Humphreys, S.M. Coordinated regulation of hormone-sensitive lipase and lipoprotein lipase in human adipose tissue in vivo: implications for the control of fat storage and fat mobilization. Adv. Enzyme. Regul. 1995, 35, 163-178.

[24] Morimoto, C.; Kameda, K.; Tsujita, T.; Okuda, H. Relationships between lipolysis induced by various lipolytic agents and hormone-sensitive lipase in rat fat cells. J. Lipid. Res. 2001, 42, 120-127.

[25] Holm, C.; Osterlund, T.; Laurell, H.; Contreras, J.A. Molecular mechanisms regulating hormone-sensitive lipase and lipolysis. Annu. Rev. Nutr. 2000, 20, 365-393.

[26] Holm, C. Molecular mechanisms regulating hormonesensitive lipase and lipolysis. Biochem. Soc. Trans. 2003, 31, 1120-1124.

[27] Haemmerle, G.; Lass, A.; Zimmermann, R.; Gorkiewicz, G.; Meyer, C.; Rozman, J.; Heldmaier, G.; Maier, R.; Theussel, C.; Eder, S.; Kratky, D.; Wagner, E.F.; Klingenspor, M.; Hoefler, G.; Zechner, R. Defective lipolysis and altered energy metabolism in mice lacking adipose triglyceride lipase. Science. 2006, 312, 734-737.

[28] Zimmermann, R.; Strauss, J.G.; Haemmerle, G.; Schoiswohl, G.; Birner-Gruenberger, R.; Riederer, M.; Lass, A.; Neuberger, G.; Eisenhaber, F.; Hermetter, A.; Zechner, R. Fat mobilization in adipose tissue is promoted by adipose triglyceride lipase. Science. 2004, 306, 1383-1386.

[29] Student, A.K.; Hsu, R.Y.; Lane, M.D. Induction of fatty acid synthetase synthesis in differentiating 3T3-L1 preadipocytes. $J$. Biol. Chem. 1980, 255, 4745-4750. 